University of Nebraska - Lincoln

DigitalCommons@University of Nebraska - Lincoln

Development of the Soil Moisture Index to Quantify Agricultural Drought and Its "User Friendliness" in Severity-Area-Duration Assessment

Venkataramana Sridhar

Kenneth Hubbard

Jinshing You

Eric D. Hunt

Follow this and additional works at: https://digitalcommons.unl.edu/natrespapers

Part of the Natural Resources and Conservation Commons, Natural Resources Management and Policy Commons, and the Other Environmental Sciences Commons

This Article is brought to you for free and open access by the Natural Resources, School of at DigitalCommons@University of Nebraska - Lincoln. It has been accepted for inclusion in Papers in Natural Resources by an authorized administrator of DigitalCommons@University of Nebraska - Lincoln. 


\title{
Development of the Soil Moisture Index to Quantify Agricultural Drought and Its "User Friendliness" in Severity-Area-Duration Assessment
}

\author{
VenKatARAMANA SRIDHAR \\ Department of Civil Engineering, Boise State University, Boise, Idaho \\ Kenneth G. Hubbard, Jinsheng You, and Eric D. Hunt \\ University of Nebraska at Lincoln, Lincoln, Nebraska
}

(Manuscript received 8 February 2007, in final form 27 November 2007)

\begin{abstract}
This paper examines the role of soil moisture in quantifying drought through the development of a drought index using observed and modeled soil moisture. In Nebraska, rainfall is received primarily during the crop-growing season and the supply of moisture from the Gulf of Mexico determines if the impending crop year is either normal or anomalous and any deficit of rain leads to a lack of soil moisture storage. Using observed soil moisture from the Automated Weather Data Network (AWDN), the actual available water content for plants is calculated as the difference between observed or modeled soil moisture and wilting point, which is subsequently normalized with the site-specific, soil property-based, idealistic available water for plants that is calculated as the difference between field capacity and wilting point to derive the soil moisture index (SMI). This index is categorized into five classes from no drought to extreme drought to quantitatively assess drought in both space and time. Additionally, with the aid of an in-house hydrology model, soil moisture was simulated in order to compute model-based SMI and to compare the drought duration and severity for various sites. The results suggest that the soil moisture influence, a positive feedback process reported in many earlier studies, is unquestionably a quantitative indicator of drought. Also, the severity and duration of drought across Nebraska has a clear gradient from west to east, with the Panhandle region experiencing severe to extreme drought in the deeper soil layers for longer periods $(>200$ days), than the central and southwestern regions (125-150 days) or the eastern regions about 100 days or less. The anomalous rainfall years can eliminate the distinction among these regions with regard to their drought extent, severity, and persistence, thus making drought a more ubiquitous phenomenon, but the recovery from drought can be subject to similar gradations. The spatial SMI maps presented in this paper can be used with the Drought Monitor maps to assess the local drought conditions more effectively.
\end{abstract}

\section{Introduction}

Soil moisture plays a vital role in linking drought, climate, and vegetation. Soil moisture data, collected from depths below the surface over the long term as well as at higher temporal and spatial resolutions, are valuable for assessing the extent and severity of drought quite accurately. There are also a variety of drought indices and a thorough description on their tractability, transparency, sophistication, extendability, and dimensionality is given by Keyantash and Dracup

Corresponding author address: Venkataramana Sridhar, Department of Civil Engineering, Boise State University, Boise, ID 83725-2075.

E-mail: vsridhar@boisestate.edu
(2002). The time interval and application of any single drought index is highly dependent on end-user needs and the location. Some of the widely applied indices include Palmer drought severity index (PDSI), standardized precipitation index, crop moisture index, Keetch-Byram drought index, and Palmer soil moisture anomaly index ( $\mathrm{Z}$ index) to name a few in a long list of indices. There are some new additions to the suite of indices such as the crop-specific stress index, which is based on the crop-specific drought index. Hubbard and $\mathrm{Wu}(2005)$ showed how corn yield is estimated by combining climate, crop yield, and soil data. The National Drought Mitigation Center (NDMC), using information compiled by the various U.S. Department of Agriculture (USDA) field offices, provides an up-to-date U.S. Drought Monitor map for use in locating the 
drought-struck areas and the impacted sectors in each climate division across the 50 states, Puerto Rico, and the Pacific possessions (NDMC 2007).

Guttman et al. (1992) and Alley (1985) reported that PDSI depicted spatially does not identify areas of equal hydrologic drought intensity owing to the variability of precipitation and groundwater levels over large areas. It suggests that PDSI, Palmer hydrologic drought index (PHDI), and streamflow and their relationship to climate signals such as El Niño-Southern Oscillation (ENSO) provides only a broad framework for regional hydrologic drought dynamics (Piechota and Dracup 1996; Timilsena et al. 2007; Tsakiris and Vangelis 2004). Therefore, an approach that is fundamentally linked to soil moisture and its measurement in the vadose zone, can only serve to enhance our ability to quantify local drought, especially during the crop-growing season, for the obvious linkages with evapotranspiration, precipitation, and deep soil moisture as reported in many studies (e.g., Sandvig and Phillips 2006; Hong and Kalnay 2000; Sheffield et al. 2004; Entekhabi et al. 1992; Koster et al. 2004). Several experimental studies reported that midlatitude agricultural droughts could be triggered by soil moisture anomalies in the early spring, when the vegetation is dormant, and subsequently continue for a sustained period through positive feedbacks (Oglesby 1991; Oglesby and Erickson 1989; Dirmeyer 1994; Sridhar et al. 2006a; Pal and Eltahir 2001). New knowledge in advance of the crop-growing season based on soil moisture has potential benefits in planning and managing water resources, selecting crops, picking seeding and transplanting times, adjusting fertilization levels, and subsequently maximizing the crop yield. Site-specific data are very valuable for improving the reliability of drought forecast and hindcast, but the expense in maintaining a network for weather and soil moisture monitoring is demanding, apart from the cost to run such a large-scale automated data network. Space-based measurements offer a compromise in measuring surface soil moisture, nonetheless, in situ measurements are second to none for measuring the entire soil column albeit continuously and are indispensable for validation.

An automated network of weather stations in the high plains (Hubbard et al. 1983) that has also measured soil moisture at $10,25,50$, and $100 \mathrm{~cm}$ continuously since 1998 provides a basis for this large-scale study. Using observed soil moisture to characterize drought at a local scale would not only help us account for vegetation stress caused by previous droughts but also eliminate either underpredicting the severity of droughts or overpredicting their duration. The objective of this study is to derive the soil moisture-based drought index, known as the soil moisture index (SMI), which provides the severity and duration of agricultural drought for each site across Nebraska during the cropgrowing season, typically between day of year (DOY) 90 and 300. Available water for plants is defined as the quantity of soil water between field capacity and the lower of limit of extractable water, which is known as the wilting point, and this stored water is extracted by plant roots (Jensen et al. 1990). Available water can therefore be an important measure to quantify agricultural drought, if it can be converted as an index. In this study, available water is first calculated based on observed or modeled soil moisture that is normalized with the maximum available water for plants calculated as the difference between field capacity and wilting point to derive the SMI. This index is classified from no drought to extreme drought to quantitatively assess drought in space and time. This method is superior to any of the indices thus far developed for the following reasons: it is based on continuous soil moisture measurements for over $8 \mathrm{yr}$, the soil texture information for the entire soil column is available to quantify available soil water, and it is extendable by combining with the in-house hydrology model for other regions and other time periods.

\section{Soil moisture observations in Nebraska}

The Automated Weather Data Network (AWDN) is a network supporting 51 soil moisture sites in $\mathrm{Ne}$ braska. This is a unique automated network with specific features including thorough calibration for each texture at each depth with extensive quality control (QC) procedures for further applications. The data are collected under rain-fed conditions and under a grass cover. There are 37 sites that have met the quality control criteria for this study and the soil moisture analysis is performed for only those sites. Figure 1 shows the location of these sites within the eight climate divisions of Nebraska. The climate division boundaries shown in Fig. 1 illustrate that the location of these sites are well distributed in the study area. The instrumentation and calibration are explained here briefly and the details are narrated in Hubbard et al. (2008, unpublished manuscript, hereafter HYSHKR). Four Theta Probes are installed at each of 51 sites in the AWDN at depths of 10, 25, 50, and $100 \mathrm{~cm}$. You and Hubbard (2006) reported the QC of the AWDN soil moisture data. The statewide soil moisture monitoring mission also undergoes quality assurance procedures and tests (HYSHKR). To identify the most suitable QC algorithm for our dataset, You and Hubbard (2006) conducted extensive testing and analysis and found that standard QC tests for climate data would not be sufficient and sub- 


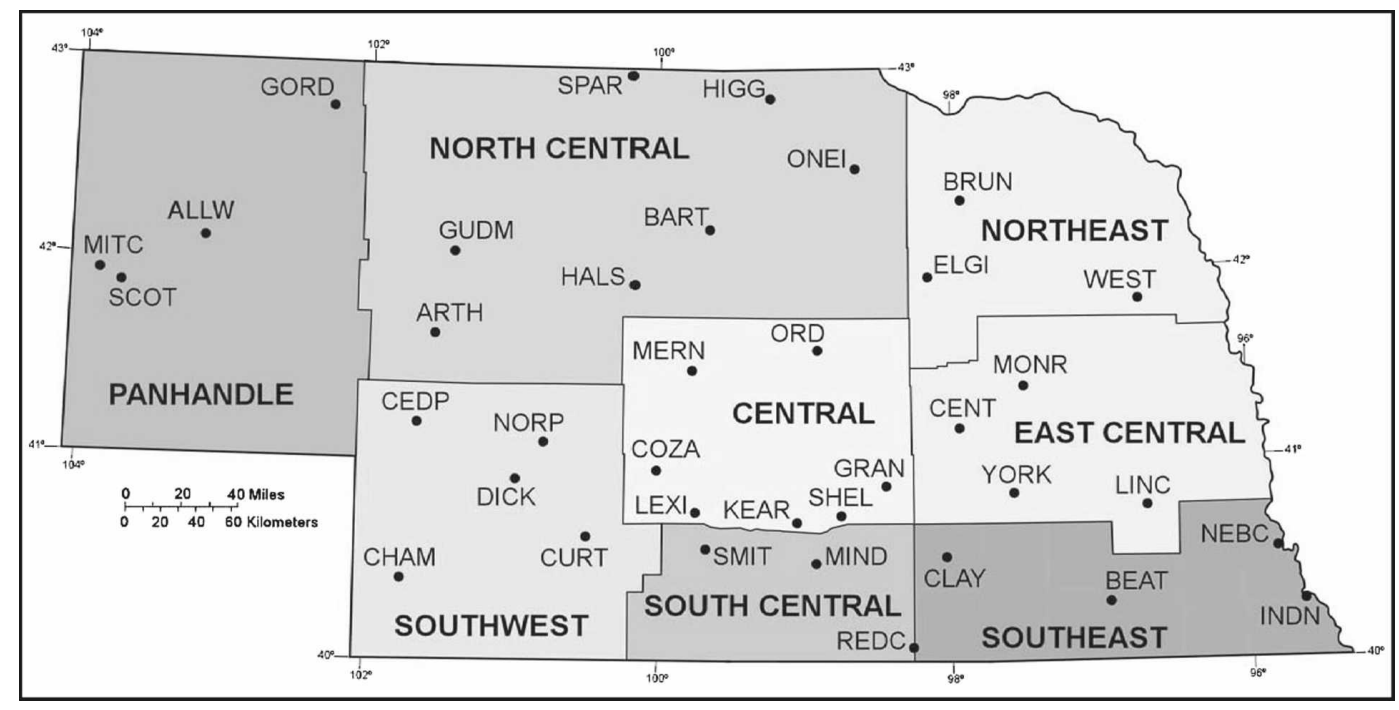

FIG. 1. Location of the soil moisture sites as collocated in the eight climate division of Nebraska.

sequently designed unique $\mathrm{QC}$ tests to soil moisture datasets. This process resulted in six useable tests based on soil moisture, soil properties, precipitation, and their statistical behavior. Spurious data due to instrumental failures were flagged through these procedures. Additionally, a spatial regression test in conjunction with the hydrology model discussed in the later sections (Robinson and Hubbard 1990) was applied to identify outliers and generate reasonable estimates for missing data (HYSHKR).

\section{Derivation of the SMI}

Among the 37 sites that are used for this investigation (Fig. 1), only 2 sites have 8 yr of data, 5 sites have $7 \mathrm{yr}, 7$ sites have $4 \mathrm{yr}$, and 23 sites have $1 \mathrm{yr}$ of data until 2005. Interannual variability in precipitation is quite high both within and across the climate divisions and the average response of soil moisture change for each of the climate divisions is moderate. Calibrated and quality controlled, the observed soil moisture dataset is made available for the current soil moisture modeling study and future drought assessment studies. Along with the soil textural information, the field capacity (FC) and wilting point (WP) for each site are assumed based on the literature values and observed soil moisture trend (Table 1). Any moisture that is in excess of FC drains from the soil and if it moves below the root zone, it is not available for plants. Also, when moisture content falls below WP, plants will not be able to extract from the soil pores and thus plants will wilt and die from lack of moisture.

The available water holding capacity (AWC) com- puted as the difference between FC and WP varies depending on the soil texture, (viz. sand, silt, and clay). In general, the sandy soils hold about $2.5 \mathrm{~cm}$ of water, silt has an AWC of $3.8 \mathrm{~cm}$, and clay has a higher AWC of $5.3 \mathrm{~cm}$ of water per $30 \mathrm{~cm}$ soil column. Some of the sites have varying soil textures among the layers for which values were assumed based on observed soil moisture pattern. The sitewise soil texture information available for each layer is taken into account when designating the values of field capacity and wilting point as shown in Table 1. The climate divisions that receive an annual precipitation of about $500 \mathrm{~mm}$ or less in the west are also sandy in most cases and their AWC is comparably less. Figure 2 shows the 30-yr annual average precipitation for each site along with the site's AWC. The annual average precipitation computed for a few sites shown in Fig. 2 are based on the AWDN dataset and the record lengths were less than $30 \mathrm{yr}$. Clearly, an increasing gradient in AWC and precipitation totals from west to east is seen from this illustration. The drought signatures analyzed from this study correlates to some extent with these visible and spectacular variations of soil moisture levels. Thus, the semiarid conditions that are present in this area provide necessary ingredients for initiating drought, especially during a low rainfall year and subsequently allowing it to persist due to the self-perpetuating condition by modifying the near-surface energy balance and vegetation characteristics.

The SMI is computed based on the soil characteristics and soil moisture conditions and the parameters include FC, WP, and soil moisture (SM). The equation is given as 
TABLE 1. Climate division, soil texture, and available water content data pertaining to the soil moisture sites in Nebraska from the High Plains Regional Climate Center (HPRCC).

\begin{tabular}{|c|c|c|c|c|c|c|c|c|c|c|}
\hline \multirow{2}{*}{$\begin{array}{l}\text { Climate } \\
\text { division }\end{array}$} & \multirow[b]{2}{*}{ Site } & \multirow[b]{2}{*}{ Site ID } & \multicolumn{4}{|c|}{ Soil texture } & \multirow{2}{*}{$\begin{array}{c}\mathrm{FC} \\
\left(\mathrm{m}^{3} \mathrm{~m}^{-3}\right)\end{array}$} & \multirow{2}{*}{$\begin{array}{c}\mathrm{WP} \\
\left(\mathrm{m}^{3} \mathrm{~m}^{-3}\right)\end{array}$} & \multirow{2}{*}{$\begin{array}{c}\text { Available } \\
\text { Water Content } \\
\left(\mathrm{m}^{3} \mathrm{~m}^{-3}\right)\end{array}$} & \multirow{2}{*}{$\begin{array}{l}\text { Water } \\
(30 \mathrm{~cm})^{-1} \\
(\mathrm{~mm})\end{array}$} \\
\hline & & & $10 \mathrm{~cm}$ & $25 \mathrm{~cm}$ & $50 \mathrm{~cm}$ & $100 \mathrm{~cm}$ & & & & \\
\hline \multirow[t]{4}{*}{ Panhandle } & Alliance west & ALLW & Sand & Sand & Sand & Sand & 0.23 & 0.14 & 0.09 & 27.4 \\
\hline & Gordan & GORD & Sand & Sand & Sand & Sand & 0.195 & 0.10 & 0.095 & 27.4 \\
\hline & Mitchell Farms & MITC & Sand & Sand & Sand & Sand & 0.19 & 0.10 & 0.09 & 30.5 \\
\hline & Scottbluff & SCOT & Silt & Silt & Silt & Silt & 0.25 & 0.13 & 0.12 & 36.6 \\
\hline \multirow[t]{7}{*}{ North-central } & Arthur & ARTH & Sand & Sand & Sand & Sand & 0.19 & 0.10 & 0.09 & 36.6 \\
\hline & Barta & BART & Sand & Sand & Sand & Sand & 0.1 & 0.05 & 0.05 & 27.4 \\
\hline & Gudmundsen & GUDM & Sand & Sand & Sand & Sand & 0.19 & 0.10 & 0.09 & 36.6 \\
\hline & Halsey & HALS & Sand & Sand & Sand & Sand & 0.12 & 0.05 & 0.07 & 45.7 \\
\hline & Higgins Ranch & HIGG & Sand & Sand & Sand & Sand & 0.1 & 0.05 & 0.05 & 39.6 \\
\hline & O’Neill & ONEL & Sand & Sand & Sand & Sand & 0.18 & 0.10 & 0.08 & 39.0 \\
\hline & Sparks & SPAR & Sand & Sand & Sand & Sand & 0.2 & 0.11 & 0.09 & 27.4 \\
\hline \multirow[t]{5}{*}{ Southwest } & Cedar Point & CEDP & Sand & Sand & Sand & Sand & 0.25 & 0.15 & 0.1 & 24.4 \\
\hline & Champion & CHAM & Silt & Silt & Silt & Silt & 0.25 & 0.13 & 0.12 & 39.6 \\
\hline & Curtis & CURT & Silt & Silt & Silt & Silt & 0.27 & 0.15 & 0.12 & 24.4 \\
\hline & Dickens & DICK & Sand & Sand & Sand & Sand & 0.19 & 0.11 & 0.08 & 27.4 \\
\hline & North Platte & NORP & Silt & Silt & Silt & Silt & 0.23 & 0.10 & 0.13 & 15.2 \\
\hline \multirow[t]{7}{*}{ Central } & Cozad & COZA & Silt & Silt & Silt & Silt & 0.28 & 0.15 & 0.13 & 39.6 \\
\hline & Grand Island & GRAN & Silt & Silt & Silt & Silt & 0.35 & 0.22 & 0.13 & 27.4 \\
\hline & Kearney & KEAR & Silts & Silt & Silt & Clay & 0.3 & 0.13 & 0.17 & 15.2 \\
\hline & Lexington & LEXI & Silt & Silt & Clay & Clay & 0.44 & 0.29 & 0.15 & 42.7 \\
\hline & Merna & MERN & Sand & Sand & Sand & Sand & 0.22 & 0.13 & 0.09 & 21.3 \\
\hline & Ord & ORD & Silt & Sand & Sand & Sand & 0.28 & 0.15 & 0.13 & 42.7 \\
\hline & Shelton & SHEL & Silt & Silt & Silt & Clay & 0.27 & 0.13 & 0.14 & 48.8 \\
\hline \multirow[t]{3}{*}{ South-central } & Minden & MIND & Silt & Silt & Clay & Clay & 0.3 & 0.12 & 0.18 & 39.6 \\
\hline & Read Cloud & REDC & Silt & Silt & Silt & Clay & 0.3 & 0.12 & 0.18 & 24.4 \\
\hline & Smithfield & SMIT & Silt & Silt & Silt & Sand & 0.3 & 0.14 & 0.16 & 39.6 \\
\hline \multirow[t]{3}{*}{ Northeast } & Brunswick & BRUN & Silt & Silt & Silt & Clay & 0.28 & 0.14 & 0.14 & 51.8 \\
\hline & Elgin & ELGI & Sand & Sand & Sand & Sand & 0.15 & 0.08 & 0.07 & 54.9 \\
\hline & West Point & WEST & Silt & Silt & Clay & Clay & 0.29 & 0.12 & 0.17 & 21.3 \\
\hline \multirow[t]{4}{*}{ East-central } & Central City & CENT & Silt & Silt & Sand & Sand & 0.28 & 0.15 & 0.13 & 54.9 \\
\hline & Lincoln & LINC & Silt & Silt & Silt & Silt & 0.32 & 0.19 & 0.13 & 57.9 \\
\hline & Monroe & MONR & Silt & Silt & Silt & Silt & 0.15 & 0.07 & 0.08 & 39.6 \\
\hline & York & YORK & Silt & Clay & Sand & Sand & 0.4 & 0.27 & 0.13 & 39.6 \\
\hline \multirow[t]{4}{*}{ Southeast } & Beatrice & BEAT & Silt & Silt & Silt & Clay & 0.39 & 0.20 & 0.19 & 54.9 \\
\hline & Clay Center & CLAY & Silt & Silt & Clay & Clay & 0.39 & 0.21 & 0.18 & 51.8 \\
\hline & Indian Caves & INDI & Silt & Silt & Silt & Silt & 0.3 & 0.11 & 0.19 & 57.9 \\
\hline & Nebraska City & NBRC & Silt & Silt & Clay & Sand & 0.35 & 0.18 & 0.17 & 51.8 \\
\hline
\end{tabular}

$$
\mathrm{SMI}=\left[\frac{5(\mathrm{SM}-\mathrm{WP})}{(\mathrm{FC}-\mathrm{WP})}-5\right]
$$

This equation yields SMI values ranging from less than -5 to 0 . That is, the actual soil moisture present in the soil column is normalized with the AWC of the soil column that is then used for computing the index. The range is chosen in a similar fashion to that of the U.S. Drought Monitor to maintain the consistency for us to compare the severity of drought from both the methods at a later stage. An SMI of 0 indicates no drought but could be heading toward drought or recovered from drought. An SMI of -1 indicates the drought of least intensity while -5 suggests that drought of extreme intensity is present for a given site (Table 2). When the actual soil moisture reaches the saturated level (field capacity) as shown in Eq. (1), SMI does not become negative and by this formulation it can only be zero.

\section{Results and discussion}

\section{a. Observed soil moisture-based SMI}

Figure 3a shows observed daily soil moisture for Mitchell Farms (MITC) between 1999 and 2005. It is located in the westernmost part of Nebraska in the Panhandle climate division. With the sandy soils in the entire column and an AWC of 0.1, it is clear that moisture is historically low at this site. From these $7 \mathrm{yr}$ of soil moisture data, the short-term gains in soil moisture in 


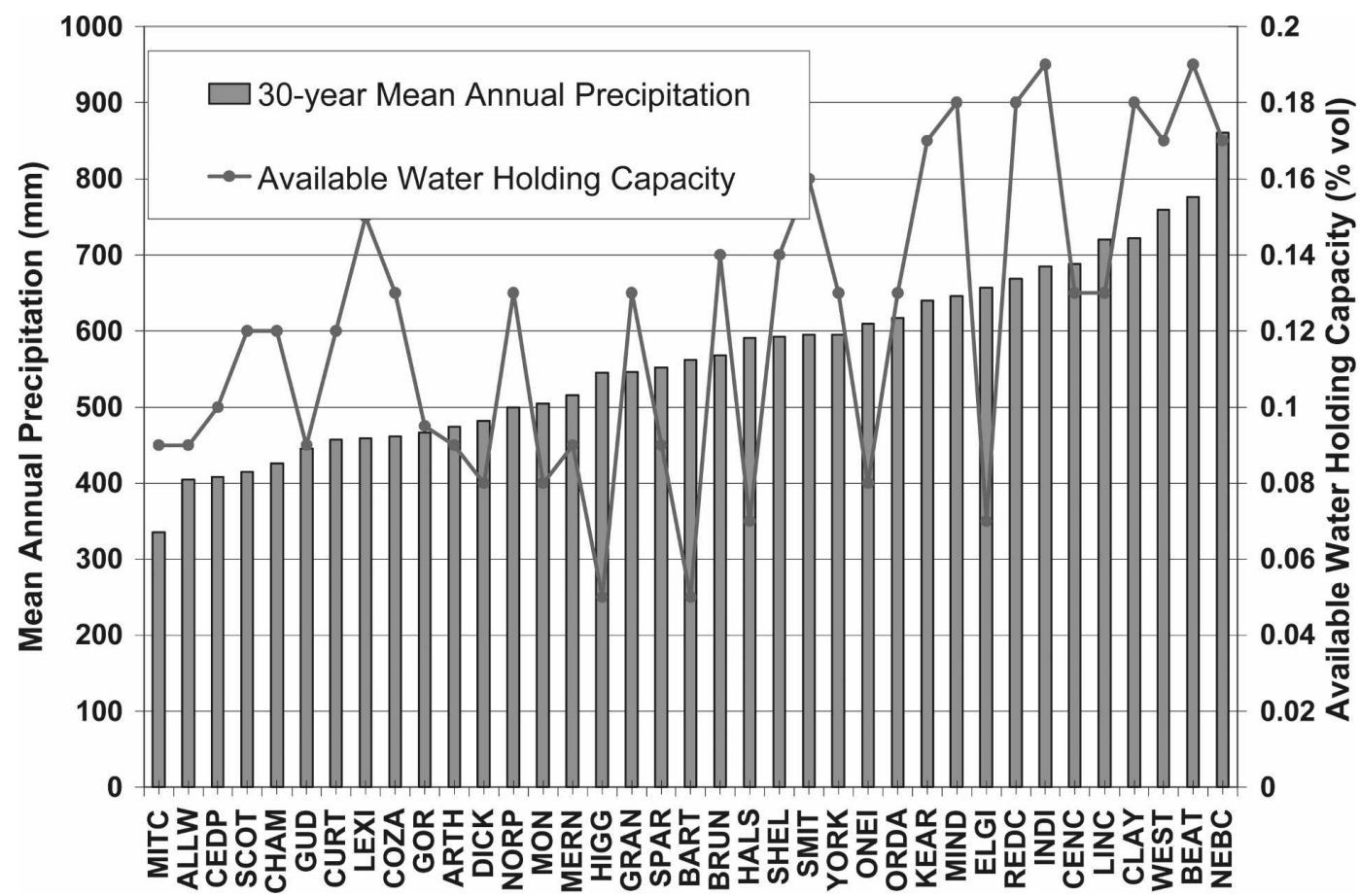

FIG. 2. Mean annual precipitation gradient shown for the soil moisture sites located from west to east in the state and their respective available water content computed based on FC and WP.

the top 10-cm layer were quite evident. This spurt in soil moisture normally coincided with a rainfall event and it occasionally reached up to volumetric water content of 0.3, once in 2000 (DOY 190) and again in 2005 (DOY 160). The fluctuations in the other three layers (i.e., 25, 50, and $100 \mathrm{~cm}$ ) were minimal. Except in 2001, $100-\mathrm{cm}$ soil moisture remained very low with moisture content of about 0.1 during the entire growing season. Another observation is that between DOY 100 and 130 in the year 2001, while surface soil moisture was lower, the other layers showed higher moisture. This may be because all layers were recharged, but the top layer was then dried by evaporation. In another instance, a notable moisture level in all four layers can be seen in 2005 between DOY 150 and 200. This suggests that short-duration convective rainfall events, which are common in the Great Plains in the spring and summer, were not large enough to recharge all four layers. It is also important to note that the 30 -yr annual average precipitation is about $335 \mathrm{~mm}$ and is the lowest of all of the sites.

The SMI derived based on observed soil moisture for all four layers is shown in Fig. $3 \mathrm{~b}$ for MITC. The 10-cm layer showed SMI nearing 0 fewer times, indicating that these are the excursions of less intense drought as either brief recovery to the drought spell or a precursor to the impending drought. When compared with the 10-cm soil moisture profile (Fig. 3a), these recovery periods correspond to that of a rainfall event. For all of the $7 \mathrm{yr}$, the 10-cm layer retracted frequently to SMI of -5 . This also suggests the tenuous nature of the upper $10-\mathrm{cm}$ layer in retreating to drought spells almost regularly. With few exceptions, the other three layers have an invariant SMI of -3 to -5 , an indication of high intense to extreme and prolonged drought in western Nebraska. The SMI range for this Panhandle site is clearly representative of this semiarid climate division where intense drought is very common and the dwindling AWC during the growing season can only get worse once the onset of drought occurs.

With respect to the southwest climate division, all four sites located in the region behaved similarly and for brevity sake illustrations are not included here. For instance, at Curtis (CURT), silt is present in all the

TABLE 2. Drought scale: SMI and the corresponding drought condition. Drought intensifies when the SMI decreases from 0.

\begin{tabular}{ll}
\hline \hline Drought condition & SMI \\
\hline Less intense & -1 or more \\
Moderate & -2 to $<-1$ \\
High intense & -3 to $<-2$ \\
Severe & -4 to $<-3$ \\
Extreme & -5 or less \\
\hline
\end{tabular}




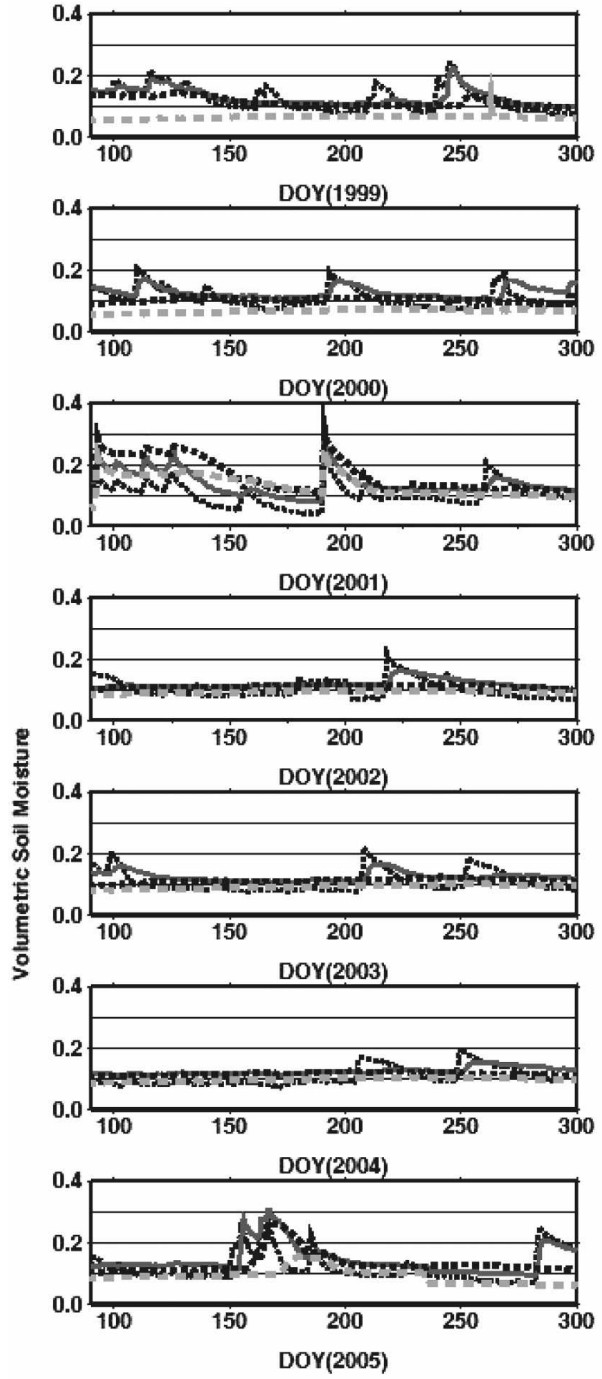

(a)
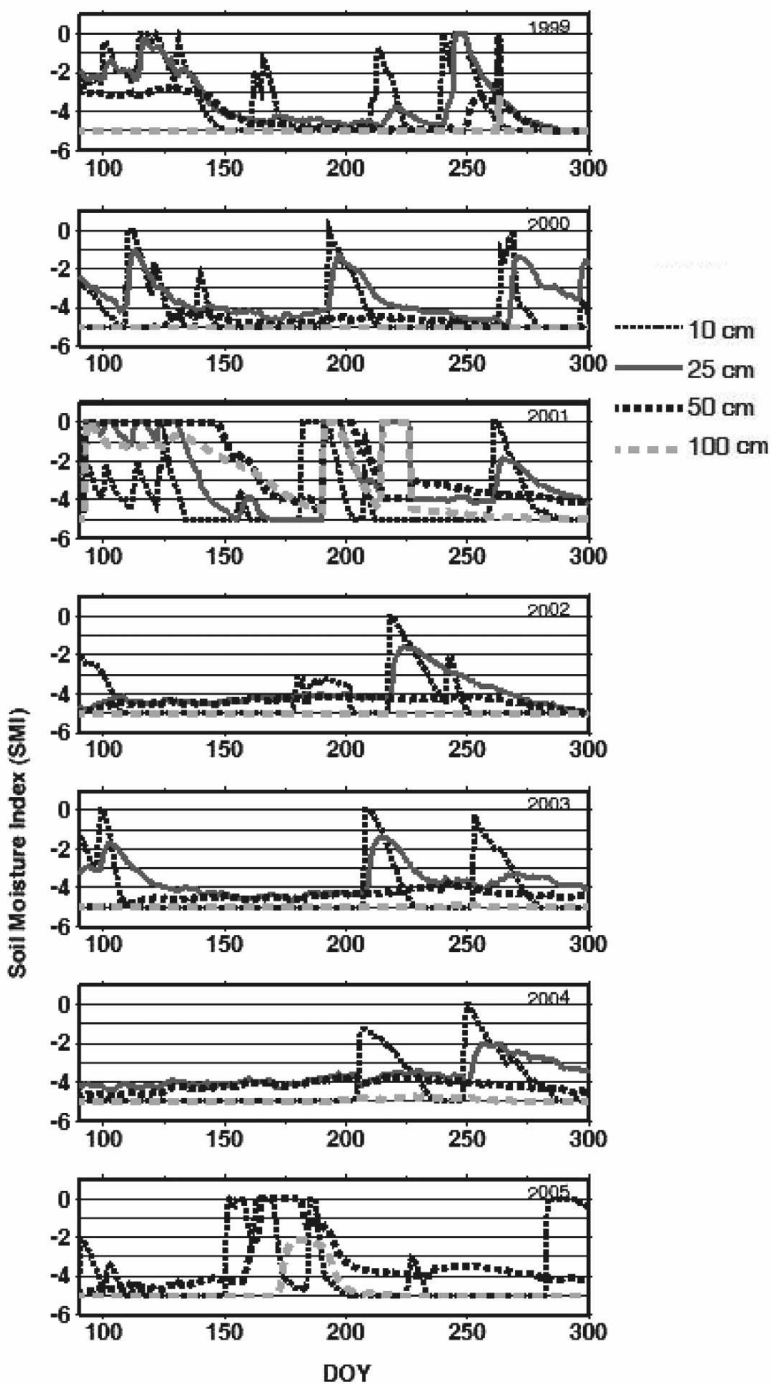

(b)

FIG. 3. (a) Observed volumetric water content at 10-, 25-, 50-, and 100-cm depths from MITC in the Panhandle climate division during the growing season (DOY 100-300) between (top to bottom) 1999 and 2005. (b) The SMI derived from observed soil moisture for MITC for the same observed periods and depths shown in Fig. 2a.

layers except the bottom-most 100-cm layer. However, the AWC computed for this based on the assumed FC and WP is 0.15 and the $30-\mathrm{yr}$ annual average precipitation is about $450 \mathrm{~mm}$. Thus, the higher precipitation amount and the silt in the top three layers augmented the high soil moisture content of $0.25-0.30$ for all $3 \mathrm{yr}$. The $100-\mathrm{cm}$ sandy soil layer contained a moisture content of 0.1 except around DOY 150 in 2005. The possibility of soil moisture recharge beneath this layer when soil moisture exceeded 0.1 was evident from the soil moisture profile. As for the SMI analysis, the upper $10-\mathrm{cm}$ layer shows an index of 0 for the first 50 days in the growing season for 2003 and 2005. This corresponds to the high moisture content for the same period and it could be attributed to the late winter and early spring precipitation/snow event. But as the growing season advanced, the depletion of soil moisture in the upper layers resulted in an SMI of -3 or less with a brief recovery after soil moisture recharged once again around DOY 240 in 2003 and 2005. For 2004, the beginning of the season indicated that including the $10-\mathrm{cm}$ layer, all layers were experiencing moderate to severe drought. But as the soil moisture content rose to 0.3 around DOY 200, the upper three layers show a recovery from drought before a general relapse into severe drought. The drop in soil moisture around DOY 250 corresponds to the end of the growing season and notably the fact that drought returned for a short duration is, 
however, of less impact as the plant water use reduces quickly at this time. It is possible to note that even toward the end of the growing season in 2003, SMI values suggest that severe to extreme drought existed, which can be attributed to the gradual depletion of soil moisture with no rainfall to break the drying cycle until the end of the season. The positive feedback between soil moisture depletion and drought is therefore gradually enhanced by midgrowing season plant water use and decreased precipitation.

The central climate division, where Kearney (KEAR) is situated received a higher amount of precipitation compared to the western climate divisions. The discussion pertaining to KEAR applies to the other sites in the central climate division as the climatic pattern and soil moisture response is somewhat similar. The $30-\mathrm{yr}$ annual average precipitation is about $625 \mathrm{~mm}$ and the soil is silt in the top three layers and clay at the bottom layer. The AWC for this site is therefore slightly higher with a value of 0.17 . The soil moisture profile showed that clearly all four layers had a high soil moisture content ranging between 0.2 and 0.45 , with the $100-\mathrm{cm}$ layer showing the highest. Relatively less moisture content can be seen in the 10-cm layer when compared with the other three layers with alternate wetting and drying trends corresponding to spring and summertime precipitation events and the crop season. Based on the computed SMI values using observed soil moisture for KEAR, it is evident that the upper 10-cm layer recovered from extreme to less intense drought and showed signs of recovery periods corresponding to periods of surge in moisture content. The severity of drought in the other layers was not quite evident until DOY 200, which approximately coincides with the middle of the growing season. Normally, the roots extend to greater depths of $50 \mathrm{~cm}$ or more, thus extracting moisture that is available in those layers. The 10-cm layer apparently recovered toward the end of the season, while the 25and $50-\mathrm{cm}$ layers did not show any sign of recovery. Interestingly, the $100-\mathrm{cm}$ layer did not experience drought for the entire year and it could be possible that plants did not extend their rooting system beyond the $50-\mathrm{cm}$ layer and therefore the moisture was not utilized (or underutilized) in the bottom layer.

The Indian Caves (INDI) site, located in the southeastern climate division receives an annual precipitation of $700 \mathrm{~mm}$ based on the 30-yr climate record and the annual precipitation in the southeast region is the highest in Nebraska with over $800 \mathrm{~mm}$. Figure 4a shows the soil moisture profile for INDI between the year 2000 and 2005. The soil type is silt in the upper three layers while the bottom layer is clay and the AWC is 0.19 . Soil moisture content in the upper layer was lower than the other three subsurface layers especially between 2000 and 2005; in particular, for the dry year 2002 , it was only about 0.1 . However, for the following years between 2003 and 2005, moisture levels in all layers bounced back to 0.3 during the beginning of the growing season. The fluctuations in the upper layer corresponded with the precipitation events and the drop in moisture content could be attributed to the drying of the layers due to plant water extraction.

The frequency of drought revisiting the upper layer at INDI is quite clear from SMI values shown in Fig. 4b, and the dynamic nature of drying and wetting periods is probably more pronounced due to the plant water extraction, evapotranspiration, and precipitation interactions at this site. While other layers were experiencing moderate to severe drought conditions, their recovery pace was slower beyond year 2002. This is partly because there was no moisture recharge from DOY 250 and the moisture tapped by the plants was not replenished and therefore a short-term self-perpetuating drought occurred in this region.

The caveat of this approach is that when the soil layer is extremely dry and soil moisture falls below WP, which can happen because of surface evaporation in the top layer, estimates of SMI become problematic. Soil moisture measurements under these conditions using the Theta Probe could be suspect. To avoid problems in calculating the SMI it is suggested that any water content that falls below the WP be considered spurious and the value, for the purpose of the calculation, be reset to the WP.

\section{b. Modeling root zone soil moisture}

Because of the difficulty in establishing a soil moisture observation-based drought index over large areas on a continuous long term, as well as for historic periods dating back to year 1900, modeling soil moisture condition and henceforth deriving drought indices should be considered as a pragmatic approach. In the event that the model captures the soil moisture pattern reasonably well, it seems reasonable to derive the SMI using simulated soil moisture for those periods when soil moisture observations are not available. Furthermore, this procedure is equally robust, both for the historical climate period and for future drought forecasting. However, in order to understand the model performance in predicting soil moisture and how they best compare with observation-based SMI, in this section the model-simulated soil moisture and the resulting pattern across the sites and climate divisions are evaluated. In the following section, evaluations are carried out for the SMI derived from soil moisture observations and compared with model-based SMI. 

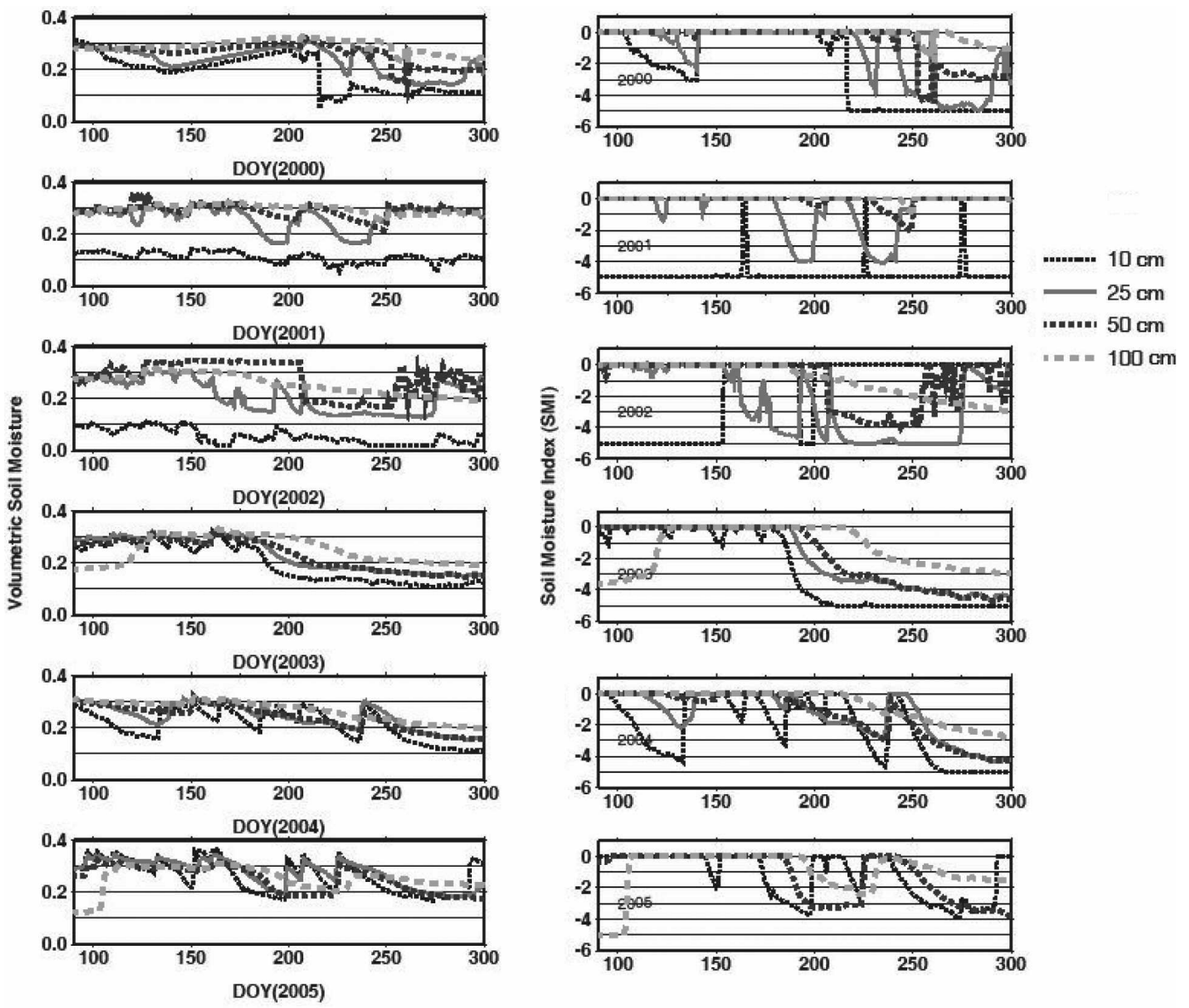

(a)

(b)

FIG. 4. (a) Observed volumetric water content at 10-, 25-, 50-, and 100-cm depths from INDI in the southeast climate division during the growing season (DOY 100-300) between (top to bottom) 2000 and 2005. (b) The SMI derived from observed soil moisture for INDI for the same observed periods and depths shown in Fig. 5a.

The hydrology model originally developed by Robinson and Hubbard (1990) has been implemented across different land-use conditions in Nebraska (Mahmood and Hubbard 2003). The recent implementation of the model in the Sandhills provides better understanding of soil moisture dynamics in the Sandhills region as well as model efficiency in predicting soil moisture from different layers (Sridhar et al. 2006b).

The fundamental equation for the soil water balance in the model is

$$
\frac{\partial S}{\partial t}=P+I-\mathrm{ET}-R-D
$$

where $S$ is soil water in the root zone $(\mathrm{mm}), t$ is time (day), $P$ is precipitation $\left(\mathrm{mm} \mathrm{day}^{-1}\right), I$ is irrigation $(\mathrm{mm}$ day $\left.^{-1}\right)$, ET is actual evapotranspiration $\left(\mathrm{mm} \mathrm{day}^{-}\right), R$ is runoff $\left(\mathrm{mm} \mathrm{day}^{-1}\right)$, and $D$ is drainage below the root zone $\left(\mathrm{mm} \mathrm{day}^{-1}\right)$. A 24-h time step is used with daily precipitation, and irrigation (not considered here) as inputs to the model. The Natural Resources Conservation Service, formerly known as Soil Conservation Service (SCS) runoff curve number, total precipitation, relative fraction of soil water present, and a soil water retention factor are adopted in the model to estimate runoff. Although, the model does not simulate runoff for time intervals shorter than a day, the daily runoff estimates are relative to the soil type in the present parameterization. Campbell's equation is used in this model to calculate drainage (Campbell 1985).

The model calculates actual evaporation $(E)$ and transpiration $(T)$ separately and the summation of the two is ET. A modified Penman (Penman 1948) combination method of potential ET estimation is used to derive actual $E$ and $T$. This modification of the Penman method incorporates a wind function developed by 
Kincaid and Heerman (1974). Actual evaporation is a function of potential ET and the number of days $(d)$ since precipitation last occurred. Actual transpiration is a function of the vegetation. The ET of a particular vegetation type or crop $\left(\mathrm{ET}_{c}\right)$ is related to the reference ET through the crop coefficient $\left(K_{c}\right)$. A phenologyspecific crop coefficient $\left(K_{c}\right)$ is multiplied by $\mathrm{ET}_{p}$ and a soil water reduction factor $(f)$. In the model, when soil moisture content approaches the wilting point, a soil water reduction factor is calculated in order to restrict transpiration. This reduction factor is a function of available soil water and water holding capacity of the soil and changes in response to the ratio of available water to potential available water.

Here in this study, again model simulations were performed at a daily time step for 1-yr periods starting in April between 1998 and 2005 and the model simulated soil moisture for five layers, at 2.5-, 27.5-, 30-, 30-, and $30-\mathrm{cm}$ depths from the surface. Instead of discussing the model predictions in detail, a brief outlook is presented on the model performance based on annual averages of the root-mean-square error (RMSE) for only 2005 as shown in Table 3. The error analysis was performed for this year because all 37 sites have data thus providing uniformity in our comparison among other sites with soil moisture observations. Observed soil moisture at $10,25,50$, and $100 \mathrm{~cm}$ was compared with the predicted values for all four layers that are relatively closer to the measurement depths. Although the model simulates at five depths, for this error analysis layer $1(2.5 \mathrm{~cm})$, layer $2(30 \mathrm{~cm})$, layer $3(60 \mathrm{~cm})$, and layer $5(120 \mathrm{~cm})$ were considered. Notice that depths of measurement versus model estimates do not exactly match, however, they are relatively close. In general, the annual average RMSE values were less than 0.10 (volumetric water content) for 23 sites, but for the remaining few sites especially at 50 and $100 \mathrm{~cm}$, RMSE values were between 0.10 and 0.15 . Only two sites, O'Neill (ONEL) and Smithfield (SMIT) had RMSE close to 0.20 where sandy soil is present at deeper depths. Both far western and eastern sites exhibited closer agreements for all layers and their RMSE were less than 0.15. It is worthwhile to note that initial soil moisture adjustments improved the predictions to some extent, but discrepancies in predictions resulting in higher RMSE could be attributed to the differences in depths between the model and observations used for these comparisons. In general, model results were better for silt and clay soils when compared with sites that had sandy soils.

Subsequently, the $30-\mathrm{cm}$ upper layer $(0-30 \mathrm{~cm})$, the $61-\mathrm{cm}$ lower layer $(30-91 \mathrm{~cm})$, and the $122-\mathrm{cm}$ root zone layer $(0-122 \mathrm{~cm})$ soil moistures were computed by reconciling the model and observation depth moistures
TABLE 3. RMSE computed from the simulated and observed soil moisture at $10,25,50$, and $100 \mathrm{~cm}$ for 37 sites used in this study.

\begin{tabular}{|c|c|c|c|c|c|}
\hline \multirow[b]{2}{*}{ Site } & \multirow[b]{2}{*}{ Site ID } & \multicolumn{4}{|c|}{$\operatorname{RMSE}\left(\mathrm{m}^{3} \mathrm{~m}^{-3}\right)$} \\
\hline & & $10 \mathrm{~cm}$ & $25 \mathrm{~cm}$ & $50 \mathrm{~cm}$ & $100 \mathrm{~cm}$ \\
\hline Mitchell Farms & MITC & 0.05 & 0.04 & 0.03 & 0.06 \\
\hline Alliance west & ALLW & 0.07 & 0.08 & 0.12 & 0.02 \\
\hline Cedar Point & CEDP & 0.07 & 0.06 & 0.06 & 0.02 \\
\hline Scottbluff & SCOT & 0.09 & 0.07 & 0.05 & 0.05 \\
\hline Champion & CHAM & 0.08 & 0.10 & 0.12 & 0.05 \\
\hline Gudmundsen & GUDM & 0.11 & 0.10 & 0.10 & 0.07 \\
\hline Curtis & CURT & 0.11 & 0.10 & 0.08 & 0.07 \\
\hline Lexington & LEXI & 0.04 & 0.04 & 0.05 & 0.05 \\
\hline Cozad & COZA & 0.08 & 0.10 & 0.07 & 0.09 \\
\hline Gordan & GORD & 0.09 & 0.10 & 0.08 & 0.04 \\
\hline Arthur & ARTH & 0.14 & 0.13 & 0.15 & 0.14 \\
\hline Dickens & DICK & 0.06 & 0.07 & 0.08 & 0.05 \\
\hline North Platte & NORP & 0.10 & 0.09 & 0.10 & 0.06 \\
\hline Monroe & MONR & 0.04 & 0.07 & 0.04 & 0.07 \\
\hline Merna & MERN & 0.13 & 0.13 & 0.14 & 0.12 \\
\hline Higgins Ranch & HIGG & 0.07 & 0.12 & 0.13 & 0.13 \\
\hline Grand Island & GRAN & 0.06 & 0.15 & 0.16 & 0.09 \\
\hline Sparks & SPAR & 0.05 & 0.05 & 0.03 & 0.06 \\
\hline Barta & BART & 0.12 & 0.11 & 0.12 & 0.15 \\
\hline Brunswick & BRUN & 0.11 & 0.10 & 0.06 & 0.14 \\
\hline Halsey & HALS & 0.04 & 0.04 & 0.05 & 0.05 \\
\hline Shelton & SHEL & 0.11 & 0.10 & 0.06 & 0.14 \\
\hline Smithfield & SMIT & 0.12 & 0.12 & 0.14 & 0.18 \\
\hline York & YORK & 0.07 & 0.08 & 0.12 & 0.02 \\
\hline O’Neill & ONEL & 0.12 & 0.12 & 0.19 & 0.05 \\
\hline Ord & ORDA & 0.08 & 0.10 & 0.12 & 0.05 \\
\hline Kearney & KEAR & 0.03 & 0.03 & 0.02 & 0.02 \\
\hline Minden & MIND & 0.05 & 0.06 & 0.06 & 0.03 \\
\hline Elgin & ELGI & 0.07 & 0.05 & 0.03 & 0.03 \\
\hline Red Cloud & REDC & 0.11 & 0.09 & 0.08 & 0.13 \\
\hline Indian Caves & INDI & 0.13 & 0.11 & 0.07 & 0.06 \\
\hline Central City & CENC & 0.10 & 0.08 & 0.06 & 0.07 \\
\hline Lincoln & LINC & 0.11 & 0.10 & 0.10 & 0.07 \\
\hline Clay Center & CLAY & 0.06 & 0.07 & 0.09 & 0.07 \\
\hline West Point & WEST & 0.03 & 0.03 & 0.04 & 0.03 \\
\hline Beatrice & BEAT & 0.11 & 0.13 & 0.15 & 0.04 \\
\hline Nebraska City & NEBC & 0.14 & 0.10 & 0.15 & 0.06 \\
\hline
\end{tabular}

with observed soil moistures. The discussion below covers the results of root zone soil moisture alone as the root zone layer comprises all the layers between 0 and $122 \mathrm{~cm}$. Annual averages of model-predicted and observed root zone soil moisture are in good agreement. In general, both observed and modeled root zone soil moisture show good agreement at the daily time scale for both the wettest (1999 and 2001) and driest years (2002) within the study period. The variability in soil moisture across the climate divisions is distinct. Sites located in western climate divisions have low moisture $(<200 \mathrm{~mm})$ while the eastern divisions sites have higher moisture $(>200 \mathrm{~mm})$.

Figure 5 presents the comparisons of model versus observed root zone soil moisture for Higgins Ranch 


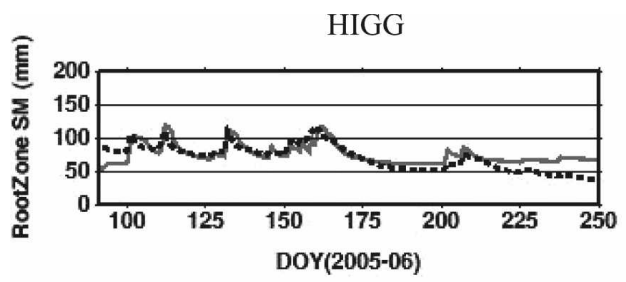

ELGI
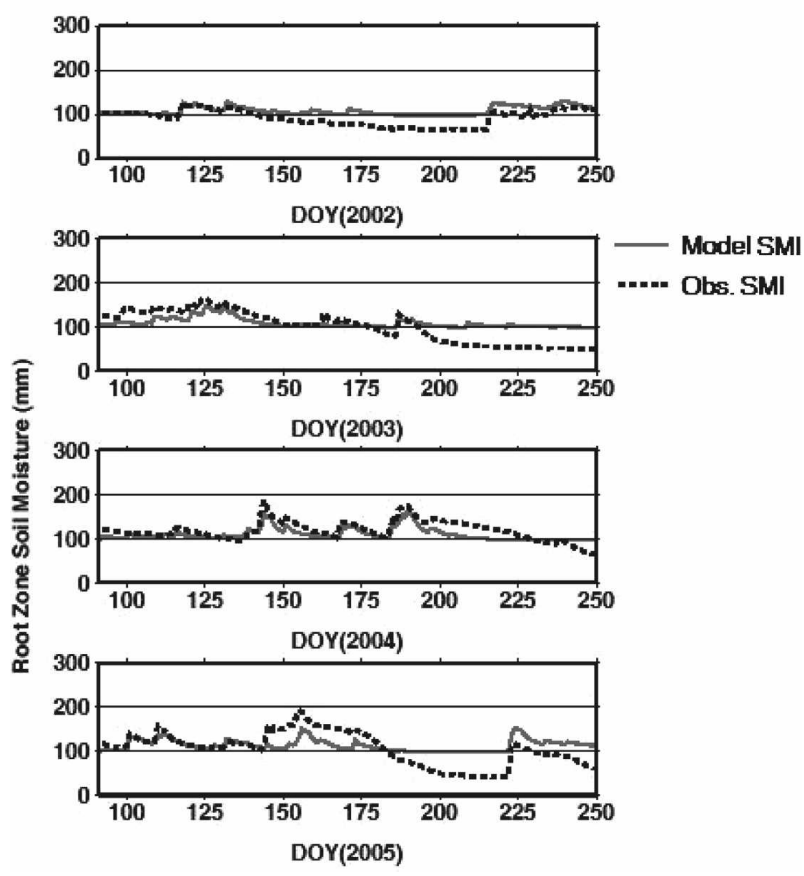

FIG. 5. Modeled and observed root zone soil moisture comparison at (left) HIGG during the growing season in 2005 and at (right) ELGI during the growing season between 2003 and 2005.

(HIGG) in the north-central division, which is also close to the Sandhills region and Elgin (ELGI), which is in the northeast climate division that receives precipitation well above $750 \mathrm{~mm}$. Even though precipitation is slightly higher than that of the Panhandle division, sandy soil with low soil water retention at HIGG results in less moisture in the root zone. Perhaps, in the Sandhills, rapid percolation of water below the root zone following precipitation events can save the water from evapotranspiration and therefore groundwater recharge is higher than what would be possible if the Sandhills were covered with loam or clay soils. The ELGI site has sandy soil, resulting in low soil moisture as seen both from the model and measurements, however, some silty soils in this region accommodate higher moisture holding capacity. Model predictions were quite good for this site with root zone moisture of about $100 \mathrm{~mm}$. However, the minor disagreements toward the end of the growing season can be attributed to some of the model parameterizations such as assumptions about soil texture, initial soil moisture, and growing degree days. For instance, a single aggregated growing degreeday (AGDD) was assumed for all years and this could vary in any particular year depending on radiation and air temperature (Sridhar et al. 2006b).

\section{c. Analysis of climate division climatology: 1998-2005}

The eastern side of the study area is composed of four climate divisions: northeast, east-central, southcentral, and the southeast. The annual total precipitation range is between 600 and $800 \mathrm{~mm}$ and soil moisture is relatively higher. The southeast climate division is the wettest with significant root zone soil moisture of up to $300 \mathrm{~mm}$ and the model underpredicts moisture as in the left panel of Fig. 6 at this annual time scale. Caution is needed in relying on observed soil moisture during winter when the performance of the sensors is questionable. Analysis of soil moisture and SMI during the growing season shown earlier is considered significant for the drought analysis. This year-to-year climate analysis is only presented to show the general pattern in the western and eastern climate divisions and to some extent to illustrate the importance of the location of Nebraska at the crosshairs of the east meeting the west for water management issues. Precipitation totals for both eastern and western Nebraska for all but year 2002 were closer to the 30-yr normal. Similarly, western Nebraska consists of four climate divisions: Panhandle, north-central, southwest, and central. However, contrary to the east, annual total precipitation in the western region is $<600 \mathrm{~mm}$, except for the central division. Soil moisture is $<150 \mathrm{~mm}$ in the Panhandle and northcentral climate divisions. The right panel in Fig. 6 shows the central and southwest region's root zone soil moisture had a range of about $200 \mathrm{~mm}$ and the model prediction was quite accurate in western Nebraska.

\section{d. Simulated soil moisture-based SMI}

We describe the results of simulated soil moisturebased SMI in this section. The assumption of FC, WP, and the resulting AWC was computed with the same values that were used for the earlier observed soil moisture-based SMI. Instead of reconciling the depths mutually to match between the simulated and observed soil moisture layers, the results of computed SMI are presented for the same model-defined depths. Figure 7 shows the computed SMI for MITC using simulated soil moisture for the period between 1999 and 2005. Obviously, the top layer, which is only $2.5 \mathrm{~cm}$, shows abundant fluctuations between extreme drought and less in- 

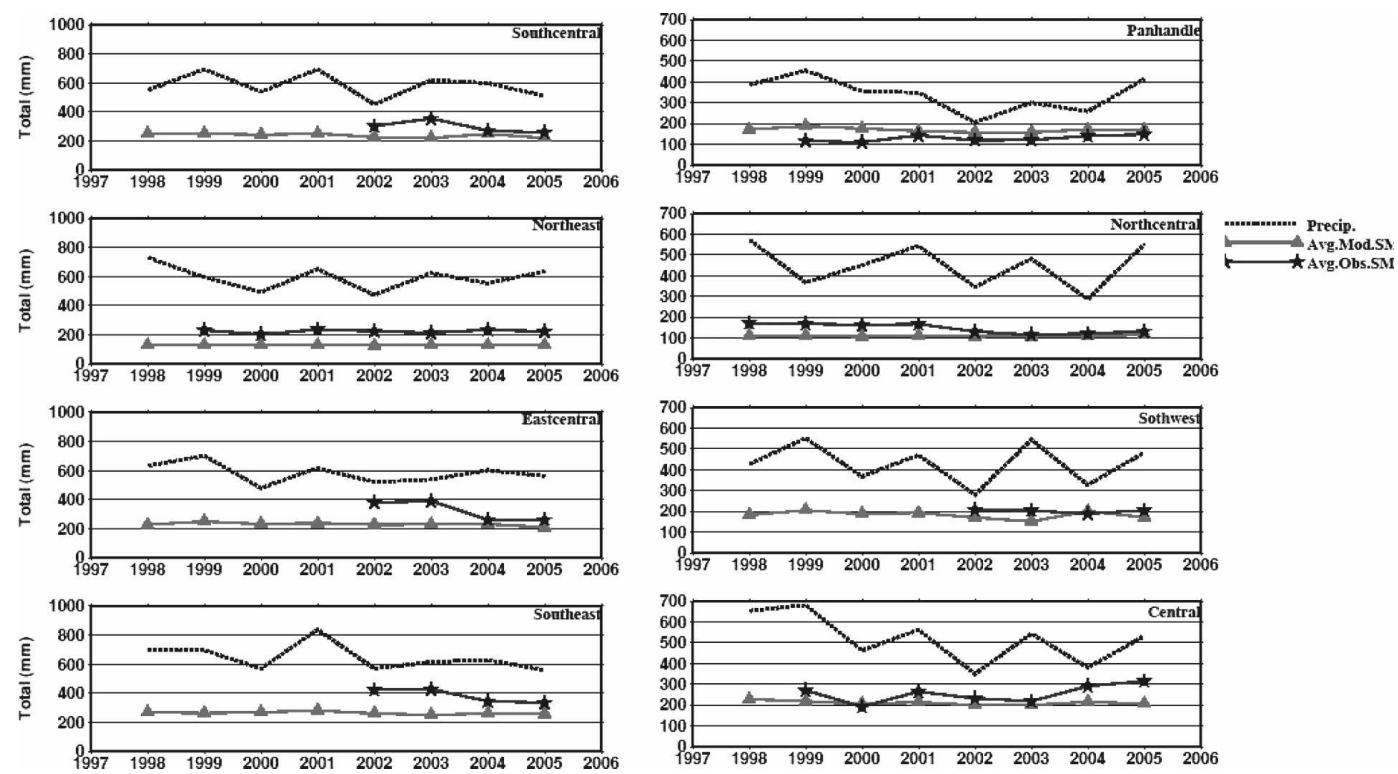

FIG. 6. Annual total precipitation and root zone soil moisture averaged over all the sites between 1998 and 2005 in each (left) eastern climate division (top to bottom) (south-central, northeast, east-central, and southeast) and (right) western climate division (Panhandle, north-central, southwest, and central).

tense drought conditions. Sandy soil at this site rapidly drains away precipitation. This was evident from the fact that the second layer at $30 \mathrm{~cm}$, where the drying and moisture recovery appeared synchronous to the top layer, but at relatively reduced intervals. This layer was comparable to the $25-\mathrm{cm}$ layer of the observed soil moisture as it captured both the less intense and the extreme drought quite closely. Especially, between DOY 100 and 150 for the period between 1999 and 2001, conditions at MITC showed an SMI of -4 but the precipitation event led to the recovery from drought similar to that observed by the soil moisture-based SMI shown in Fig. 2b. The SMI derived for 60, 90, and 120 $\mathrm{cm}$ agreed closely with the SMI derived from observed soil moisture at $50-$ and $100-\mathrm{cm}$ depths.

Our analysis on how many days drought persisted as well as its severity for a given year based on the histogram representation for MITC is shown in Fig. 8. An attempt was also made to compare layers 2, 3, and 4 between the model- and observation-based SMI and as before the depths of comparison would be slightly different based on model layer configuration and soil moisture sensor locations. In essence, comparisons were made between model versus observed SMI as 30 $\mathrm{cm}$ against $25 \mathrm{~cm}, 60 \mathrm{~cm}$ against $50 \mathrm{~cm}$, and $90 \mathrm{~cm}$ against $100 \mathrm{~cm}$, for layers 2,3 , and 4 , respectively. One of the most interesting features about this illustration is that MITC consistently exhibited extreme drought $(\leq-5)$ for all the years close to 200 days in a year that is very common for this Panhandle region. Although there were some differences in the number of days between the model and observed SMI in layers 2 and 3, the agreements on the drought severity were generally close. Except 2001 and 2005, other years were dominated by droughts between severe and extreme droughts. Therefore, year after year the recurrence of the self-perpetuating drought at deeper depths was abundantly clear and in the past 7 yr between 1999 and 2005 , it appeared that drought at these depths never recovered. This also supports the theory proposed by many studies including Entekhabi et al. (1992) and Nicholson (2000) that the recovery from the dry to wet state could be slower due to land surface-atmosphere interaction and positive feedbacks.

Figure 9 exhibits the SMI derived using modeled soil moisture for 6 yr between 2000 and 2005 at INDI. Similar to the other sites, the top layer shows frequent fluctuations as the moisture content in the layer changes in response to precipitation and drying events. However, the agreements seen for the other four layers in Fig. 9 with that of Fig. 4b cannot be overstated. The second layer showed extreme drought in the initial growing season between days 100 and 150 , but recovery was quite remarkable for all of the years except 2003. This was quite close to the scenario that is observed based on the soil moisture measurements. The $120-\mathrm{cm}$ layer shows no signs of severe drought that matches with 100-cm SMI in Fig. 4b. From Fig. 10, INDI, located in the wettest portion of the state had less than 100 days of drought and note, extreme drought in layer 3 exceeding 

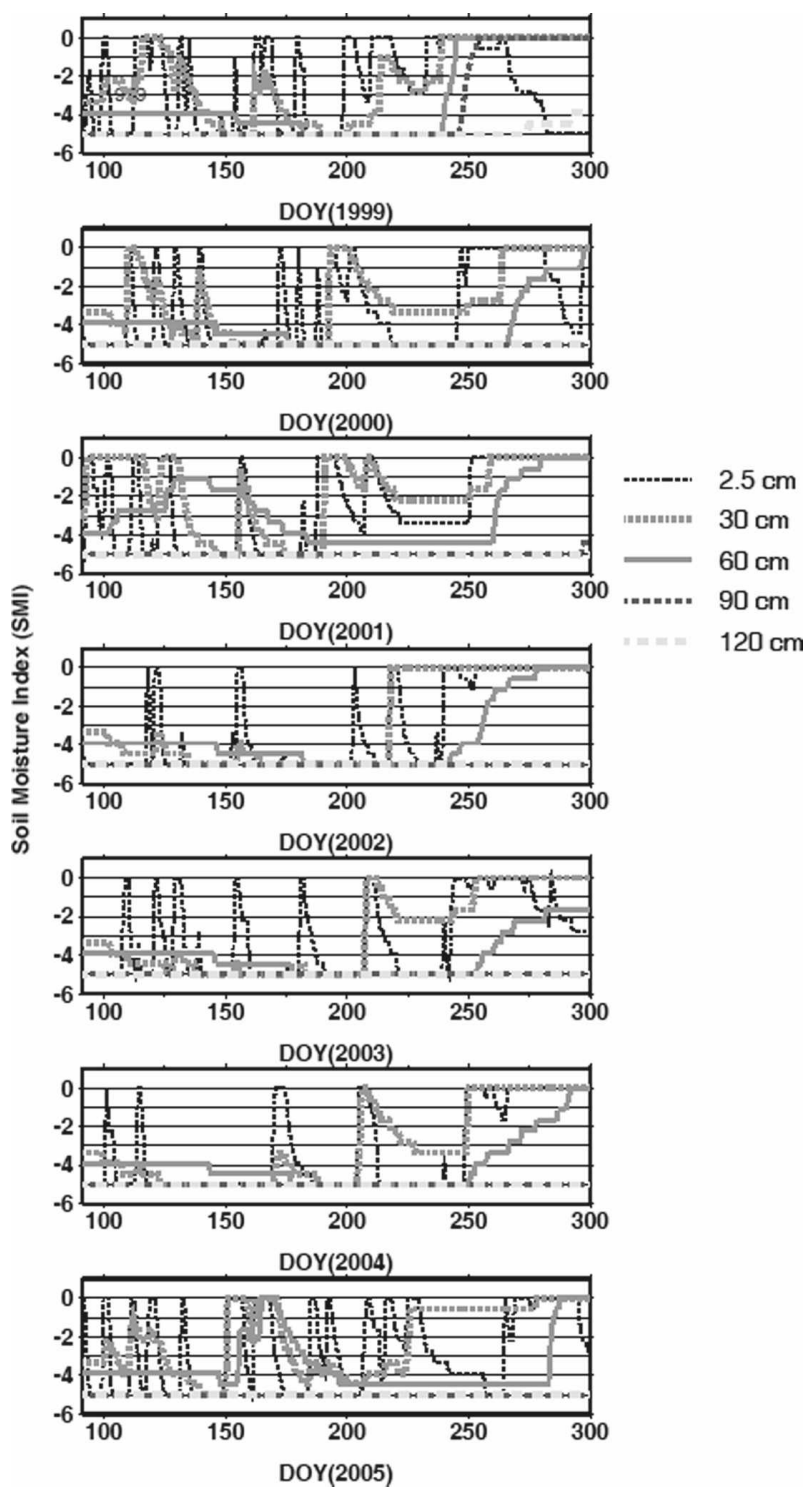

FIG. 7. Modeled SMI at 10-, 25-, 50-, and 100-cm depths for MITC during the growing season between (top to bottom) 1999 and 2005.

200 days was seen only once in 2001 in the entire $6 \mathrm{yr}$ of analysis. While varying degrees of drought persisted between 50 and 100 days, the frequency with which the wet and dry conditions alternated, presented an interesting phenomenon as suggested by Entekhabi et al. (1992), that recovery from the wet state was much faster. Notably, this region receives the highest precipitation amount in the entire state.

Based on the point observations and modeling results of soil moisture pattern from 37 sites, a spatial interpolation procedure using spline interpolation method in the ArcGIS software environment was performed to generate the drought maps. The spatial analysis was performed using both the deterministic (inverse distance and spline) and statistical (kriging) methods. The spline interpolation technique was employed in our analysis as it represented a better estimator, given the density of soil moisture sites. Figure 11 shows the snapshot view of drought at $50-\mathrm{cm}$ depth for observations, $60 \mathrm{~cm}$ for modeling from DOY 100 and 200, which comes within the growing season of 2005. The spatial drought maps were also compared with an operational drought product, popularly known as the U.S. Drought Monitor from the NDMC. The Drought Monitor was used for this comparison as it is derived from many indices including PDSI, the standardized precipitation index (SPI), and the satellite vegetation health index. However, the Drought Monitor maps can only be used as a general reference. The NDMC cautions against using it as an accurate representation of drought for a particular area and recommends that drought conditions need to be reassessed when more local information such as soil moisture or other environmental variables are available. The correspondence of soil moisture indices with the Drought Monitor map of the two closest days, DOY 102 (12 April 2005) and DOY 200 (19 July 2005) were checked with DOYs 100 and 200. Despite differences in layer depths used to compare among observations, simulation, and the Drought Monitor maps, the general agreement is obvious for both the spatial extent and intensity of drought. The southwest region identified as severe to exceptional drought by the Drought Monitor matched very well with observations and model results for both the days. Similarly, baring the northeastern region, severe to extreme drought predicted by the model and Drought Monitor agreed very well. The Sandhills region showed no or mild drought, which compared very well, especially toward the end of the growing season. This condition is common in the late summer or early fall when the evapotranspiration in the Sandhills is reduced from 5 to $3 \mathrm{~mm} \mathrm{day}^{-1}$ due to plant senescence and the moisture availability is increased in the Sandhills and hence the recharging of the Ogallalla Aquifer. However, a difference of $10 \mathrm{~cm}(50$ versus $60 \mathrm{~cm})$ in the soil moisture observations between observed and modeled results can be attributed to the spatial mismatch in the drought extent and intensity. Thus, for predicting drought more accurately for a particular location or a region, local information such as soil moisture can be very valuable.

Although the model-based SMI for CURT between 2003 and 2005 is not shown, the general pattern of recovery of moisture and drying matched well with the observations. The discrepancy appeared obvious only at the $50-\mathrm{cm}$ depth where soil moisture did not seem to 

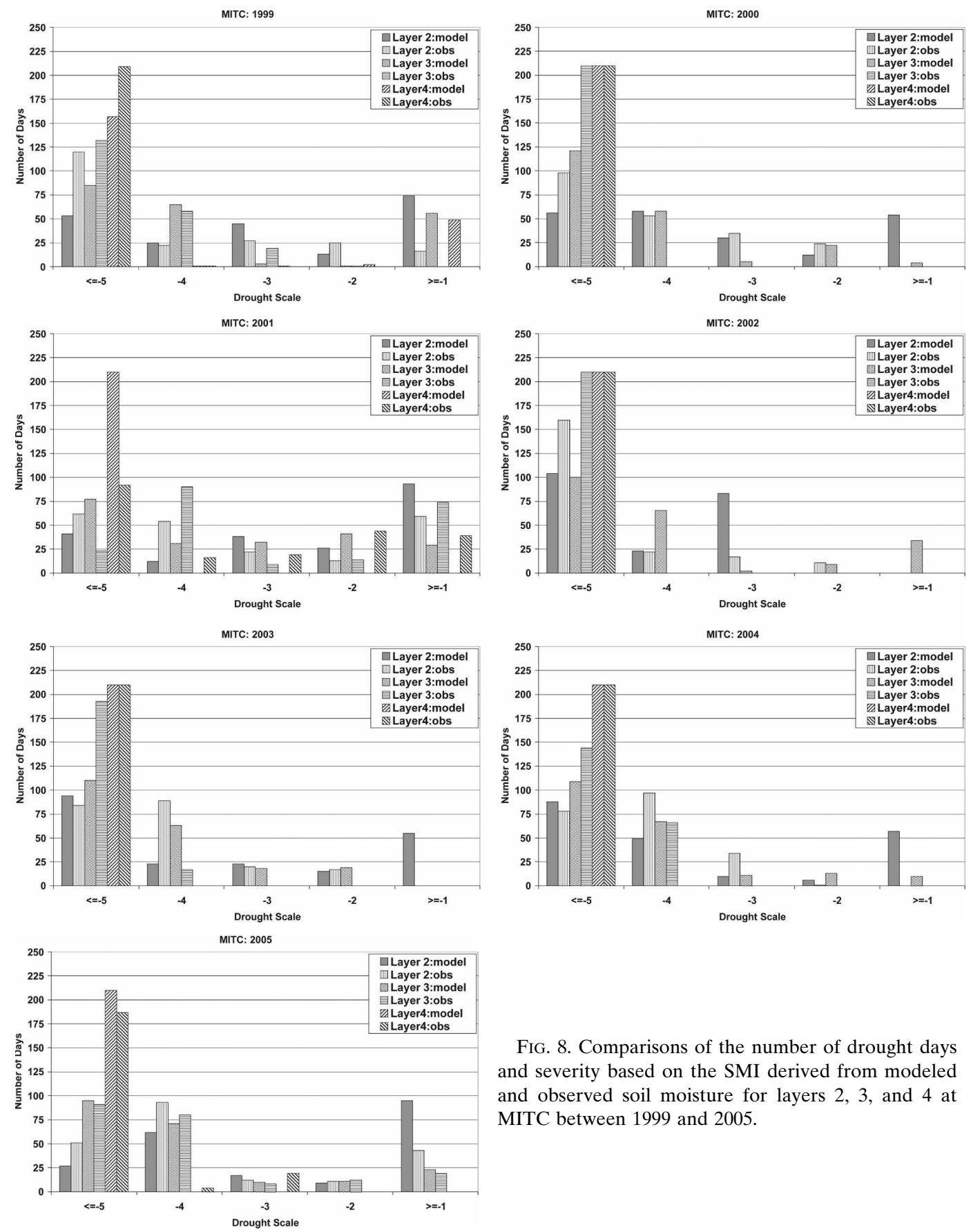

be retained, whereas the observations showed a decrease in the severity of drought around DOY 150. This could be due to the changing texture with depth from silt to sand in the soil column (Table 1). However, as the growing season advanced the top two layers recovered from extreme drought and both observation- and model-based indices matched well. Extreme drought for 175-200 days in 2005 for CURT suggested that this site experienced drought that is common in the south-

west region. About 50 days of severe drought existed at this site, however, less intense drought $(\geq-1)$ in layer 2 showed some discrepancy between the model and observation-based SMI (Fig. 11). Simulations results for the central climate division site, KEAR for 2005 was very closely matching with the observation-based SMI. Notably, the upper layer from both observed and modeled SMI showed depletion of moisture more frequently and rapidly thereby a sustained drought condi-

FIG. 8. Comparisons of the number of drought days and severity based on the SMI derived from modeled and observed soil moisture for layers 2,3 , and 4 at MITC between 1999 and 2005.$$
\text { quently and rapidly thereby a sustained drought condi- }
$$ 

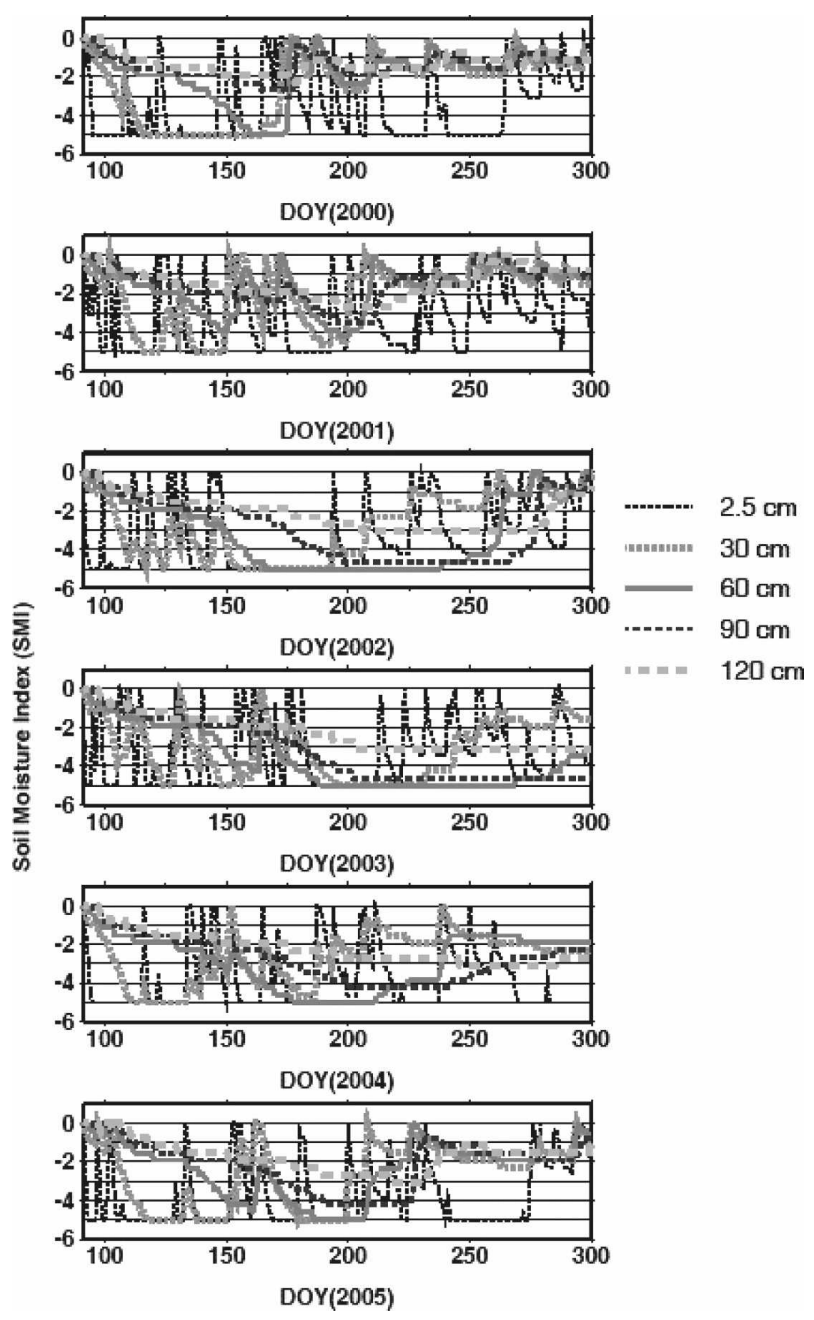

FIG. 9. Modeled SMI at 10-, 25-, 50-, and 100-cm depths from INDI during the growing season between (top to bottom) 2000 and 2005.

tion was visible. The second and third layers appeared to have bounced back from extreme drought around DOY 170 and the correlation was in line with that of observation-based SMI. Furthermore, the bottom layer had the highest soil moisture as the soil is clay, which mostly remained in dry or mild drought conditions for the entire year. The number of drought days was between 100 and 150 days, far less than those of the sites in western Nebraska. Also, while the model overpredicted the extreme drought $(\leq-5)$, it was underpredicting the severe drought $(-4)$ by a few days. In all, the general pattern of reduced drought days in central Nebraska is evident.

The analysis suggests that the model-based SMI has the potential to represent the drought conditions that would otherwise be unavailable for those areas where soil moisture measurements are not collected. Al- though soil moisture simulations were performed for all of the 37 sites shown in Fig. 1 and SMI values were calculated for each site based on observed and modeled soil moisture, results are shown for only four sites representing different regions within Nebraska. This is expected to serve as the basis for emphasizing the importance of drought and soil moisture analysis for our future predictions.

\section{Summary and conclusions}

This study utilizes the extensive and unique soil moisture dataset that is available for more than 37 sites in Nebraska. The Great Plains region receives the most rainfall during spring and summer when a predominantly southerly flow transports moisture from the Gulf of Mexico to the Plains. Notably, the growing season rainfall between April and October across Nebraska amounts to nearly $90 \%$ of the annual total. If there is an anomaly in the circulation pattern combined with seasonal and annual regional vagaries of weather, the supply of moisture to this region may cease or be greatly diminished. In turn, the availability of soil moisture in the root zone for the crops will become drastically reduced. Part of the state of Nebraska also consists of the Sandhills, a region known for characteristic droughts and hence, the grasslands management for the stability of the dunes that exist in the Sandhills becomes vital. To have a better understanding of soil moisture dynamics and its role in droughts of the high plains region, an index that suggests both duration and severity of drought is critical. An index to quantify drought, called a soil moisture index (SMI) is derived using the soil moisture datasets collected for the past $8 \mathrm{yr}$ between 1998 and 2005. From the results of this study, we conclude the following:

- The range in precipitation $(335-860 \mathrm{~mm})$, based on the 30 -yr average annual totals, is quite consistent with the gradient in available water holding capacity (AWC) computed as the difference between field capacity (FC) and wilting point (WP) across the region.

- SMI developed based on the actual soil moisture and computed AWC for the observed soil moisture portrayed a clear picture of extreme drought that persisted in already drought-prone areas (Panhandle and the southwest) and in preceding times on the annual scale, particularly impacted by rainfall leading up to the growing season and moderate droughts in central and southeastern climate divisions.

- We also propose that simulated soil moisture that is in line with observed soil moisture can play a crucial role in extending observed soil moisture-based SMI to simulated soil moisture-based SMI. Noting the 

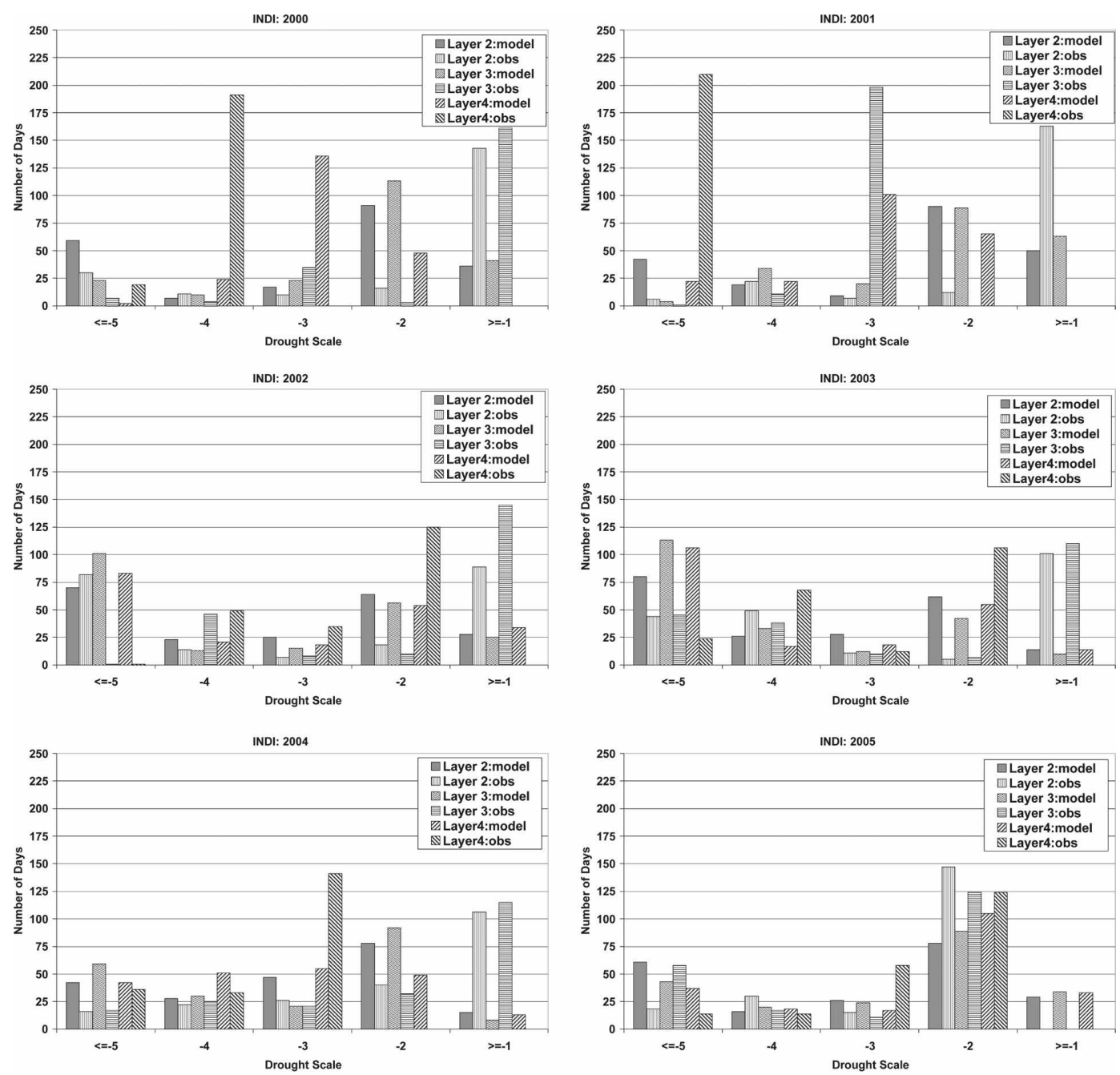

FIG. 10. Comparisons of the number of drought days and severity based on the SMI derived from modeled and observed soil moisture for layers 2, 3, and 4 at INDI between 2000 and 2005.

variations in annual precipitation between eastern and western sites of up to $500 \mathrm{~mm}$, predicted soil moisture across the range of sites in general, exhibited closer agreement for all layers with RMSE less than 0.15 . By appropriately providing the soil characteristics, systematic errors were reduced to some extent. For example, while the FC and WP values were fixed for all the years, these values were based on the range of observed soil moisture conditions and some educated assumptions. However, the initial soil moisture conditions provided for the model were based on the first year of observed soil moisture and to remove any systematic error, year-to-year adjustments of these values for each layer are recommended.

- Finally, the SMI values, based on simulated soil moisture for each of the five layers, were compared with the observation-based SMI through spatial and time series analysis. Clearly, SMI agreed well during this growing season comparison across the sites in terms of onset, persistence, severity, and recovery. The dry conditions in southwest Nebraska, predicted from soil moisture, matched well with drought areas on the Drought Monitor maps. It is concluded that the SMI maps can be used in conjunction with the Drought Monitor maps to derive local drought conditions more accurately and this can also be used to improve drought forecasting. The Sandhills region showed drought at the beginning of the growing season but the region recovered normally toward the end of the growing season. The agreement on number of days of a prescribed drought between predicted and observation-based SMI cannot be overstated. While low precipitation regions in the west had about 200 days 

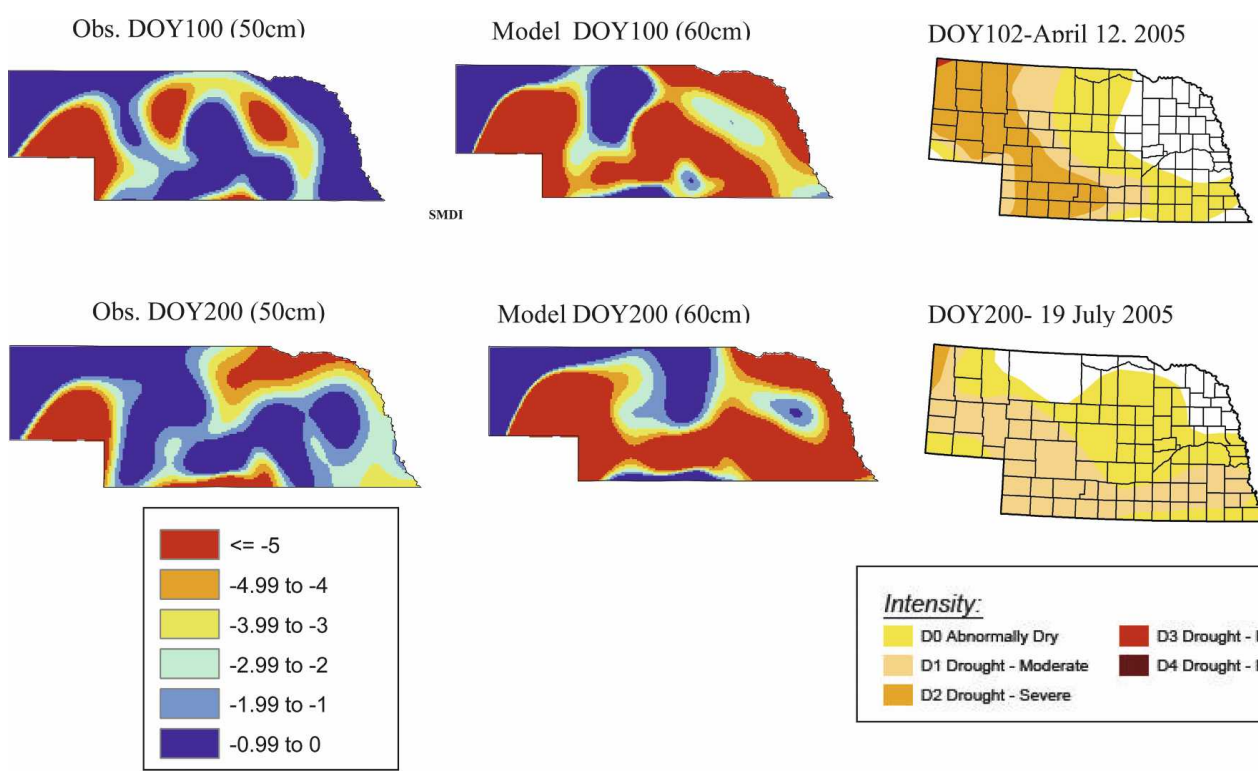

DOY200- 19 July 2005
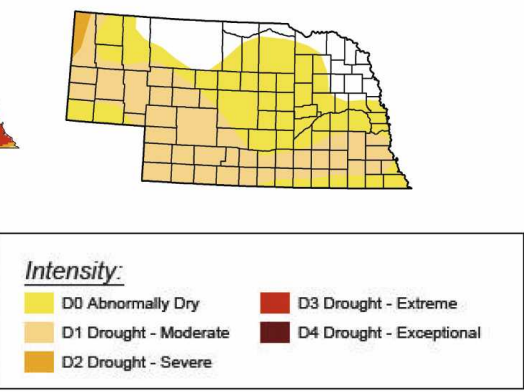

FIG. 11. Spatial comparisons of observed and modeled SMI with the Drought Monitor map (Source: National Drought Mitigation Center with Legend D0-D4) during the growing season of 2005.

or more of deeper soil layer droughts from severe to extreme conditions, the central region showed droughts of lesser severity and had a duration of about $125-150$ days, and the eastern sites showed a remarkable drought duration of about 100 days or so.

This study reinforces our claim that predicted soil moisture can be a useful tool for estimating SMI in the absence of soil moisture measurements. It should be recognized that SMI is related to plant water availability and hence it is closely associated with agricultural drought, and other droughts such as meteorological or hydrological drought (based on the streamflow conditions) are not addressed in this context. Over all, the SMI could be a reliable measure for us to implement across the network of stations to quantify drought both in historical and future time scales for managing water and land resources. Numerous past studies shed light on how soil moisture and drought can be intricately linked through the land surface feedback processes, mostly through modeling only. Our results validate those studies and extend the evidence by using the unique soil moisture datasets for the quantification of drought that, in turn, can be an operational tool in the near future.

Acknowledgments. We thank the Agricultural Research Division of the University of Nebraska at Lincoln for the support provided through the Agriculture and Water Research Endowment Grant to conduct this study. The authors are also grateful to the anonymous reviewers and the chief editor for their helpful comments toward improving the original manuscript. The senior author gratefully acknowledges the support provided in part by the NSF-Idaho EPSCoR Program and NSF Award No. EPS-0447689.

\section{REFERENCES}

Alley, W. M., 1985: The Palmer Drought Severity Index as a measure of hydrologic drought. Water Resour. Bull., 21, 105-114.

Campbell, G. S., 1985: Soil Physics with Basic. Elsevier, 150 pp.

Dirmeyer, P. A., 1994: Vegetation stress as a feedback mechanism in midlatitude drought. J. Climate, 7, 1463-1483.

Entekhabi, D., I. Rodriguez-Iturbe, and R. L. Bras, 1992: Variability in large-scale water balance with land surface-atmosphere interaction. J. Climate, 5, 798-813.

Guttman, N. B., J. R. Wallis, and J. R. M. Hosking, 1992: Spatial comparability of the Palmer Drought Severity Index. Water Resour. Bull., 28 (6), 1111-1119.

Hong, S.-Y., and E. Kalnay, 2000: Role of sea surface temperature and soil-moisture feedback in the 1998 Oklahoma-Texas drought. Nature, 408, 842-844.

Hubbard, K. G., and H. Wu, 2005: Modification of a crop-specific drought index for simulating corn yield in wet years. Agron. J., 97, 1478-1484.

—, N. J. Rosenberg, and D. C. Nielsen, 1983: An automated weather data network in support of agricultural operations. $J$. Water Resour. Plann. Manage., 109, 213-222.

Jensen, M. E., R. D. Burman, and R. G. Allen, Eds., 1990: Evapotranspiration and irrigation water requirements. ASCE Manual and Reports on Engineering Practice No. 70, Irrigation and Drainage Division of the American Society of Civil Engineers, $332 \mathrm{pp}$.

Keyantash, J., and J. A. Dracup, 2002: The quantification of drought: An evaluation of drought indices. Bull. Amer. Meteor. Soc., 83, 1167-1180. 
Kincaid, D. C., and D. F. Heerman, 1974: Scheduling irrigations using as programmable calculator. USDA-ARS-NC-12, 55 pp.

Koster, R. D., and Coauthors, 2004: Regions of strong coupling between soil moisture and precipitation. Science, 305, 11381140, doi:10.1126/science.1100217.

Mahmood, R., and K. G. Hubbard, 2003: Simulating sensitivity of soil moisture and evapotranspiration under heterogeneous soils and land uses. J. Hydrol., 280, 72-90.

NDMC, cited 2007: U.S. drought monitor. National Drought Mitigation Center, University of Nebraska-Lincoln. [Available online at http://www.drought.unl.edu/dm/.]

Nicholson, S., 2000: Land surface processes and sahel climate. Rev. Geophys., 38, 117-139.

Oglesby, R. J., 1991: Springtime soil moisture, nature climate variability, and North American drought as simulated by the NCAR Community Climate Model I. J. Climate, 4, 890-897.

— North American drought. J. Climate, 2, 1362-1380.

Pal, J. S., and E. A. B. Eltahir, 2001: Pathways relating soil moisture conditions to future summer rainfall within a model of the land-atmosphere system. J. Climate, 14, 1227-1242.

Penman, H. L., 1948: Natural evapotranspiration from open water, bare soil and grass. Proc. Roy. Soc. London, 193A, 120145.

Piechota, T. C., and J. A. Dracup, 1996: Drought and regional hydrologic variation in the United States: Associations with the El Niño-Southern Oscillation. Water Resour. Res., 32 (5), 1359-1373.
Robinson, J. M., and K. G. Hubbard, 1990: Soil water assessment model for several crops in the high plains. Agron. J., 82, 1141-1148.

Sandvig, R. M., and F. M. Phillips, 2006: Ecohydrological controls on soil moisture fluxes in arid to semiarid vadose zones. $\mathrm{Wa}$ ter Resour. Res., 42, W08422, doi:10.1029/2005WR004644.

Sheffield, J., G. Goteti, F. Wen, and E. F. Wood, 2004: A simulated soil moisture based drought analysis for the United States. J. Geophys. Res., 109, D24108, doi:10.1029/ 2004JD005182.

Sridhar, V., D. B. Loope, J. A. Mason, J. B. Swinehart, R. J. Oglesby, and C. M. Rowe, 2006a: Large wind shift on the Great Plains during the Medieval warm period. Science, 313 (5785), 345-347, doi:10.1126/science.1128941.

—, K. G. Hubbard, and D. A. Wedin, 2006b: Assessment of soil moisture dynamics of the Nebraska Sandhills using long-term measurements and a hydrology model. J. Irrig. Drain. Eng., 132 (5), 463-473, doi:10.1061/(ASCE)07339437(2006)132:5(463).

Timilsena, J., T. C. Piechota, H. Hidalgo, and G. Tootle, 2007: Five hundred years of hydrological drought in the upper Colorado river basin. J. Amer. Water Resour. Assoc., 43 (3), 798812, doi:10.1111/j.1752-1688.2007.00064.x.

Tsakiris, G., and H. Vangelis, 2004: Towards a drought watch system based on spatial SPI. Water Resour. Manage., 18, 1-12.

You, J., and K. G. Hubbard, 2006: Quality assurance of soil moisture data in ACIS-A case study in Nebraska. High Plains Regional Climate Center Rep., 31 pp. 